www.jmscr.igmpublication.org

Impact Factor (SJIF): 6.379

Index Copernicus Value: 71.58

ISSN (e)-2347-176x ISSN (p) 2455-0450

crossrefDOI: https://dx.doi.org/10.18535/jmscr/v6i6.186

Journal Of Medical Science And Clinical Research

\title{
Evaluation of impact of teaching critical appraisal of drug promotional literature among medical interns using WHO guidelines
}

\author{
Authors \\ Hasina Sayyad ${ }^{1}$, Tiwari S.A ${ }^{2 *}$, Ghongane B.B ${ }^{3}$ \\ ${ }^{1,2}$ Lecture, ${ }^{3}$ Prof. and Head of Department \\ Department of Pharmacology, BJ Government Medical College, Pune, India \\ *Corresponding Author \\ Tiwari S.A \\ Lecture, Department of Pharmacology, BJ Government Medical College, Pune, India
}

\begin{abstract}
Objectives: To sensitize the medical interns regarding aspects of WHO criteria and other essential information for drug promotion and to determine the impact of teaching critical appraisal of promotional literature.

Methods: 151 medical interns answered a pre-test questionnaire. They were also asked to evaluate five promotional literatures for pre knowledge testing of ability to identify violations of existing WHO guidelines for promotional literature. This was followed by a lecture on WHO criteria for drug promotional literature and other related important information required for prescribing any drug (Indication, ADR, Monitoring, contraindications, drug interactions, clinical trial results, medical body recommendation, specialist testimonials, Significance of references presented).This activity was followed by small group discussions. End of the session, each intern had to answer a post-test questionnaire and was evaluated accordingly.

Result: Statistically significant improvement $(p<0.0001)$ was observed in post-test questionnaire score as regards to the gain in knowledge about all the WHO criteria that appeared in promotion literature. These criteria were required for prescribing any drug (eg .brand name, ADR, etc.).The success of training interns for other essential information required for prescribing tool, reflected as a statistical significant improvement in knowledge $(p<0.0001)$ in the post-test evaluation.

Conclusion: This study highlights the importance of training medical interns on the topic of "critical appraisal of drug promotional literature". It is reasonable to conclude that the problem of irrational drug use may significantly reduce, if prescribing doctors are able to critically appraise the claims made in drug promotional materials. Future prescribing practices may improve if the necessary skills and critical attitudes for rational therapy are strengthened during the internship of medical undergraduates.
\end{abstract}

\section{Introduction}

In this era where aggressive marketing of pharmaceutical products especially drugs is rampant; the promotional literatures play a critical role. Promotional literatures are one of the armaments to reach the physicians via Pharmaceutical representatives. Pharmaceutical promotional activities have powerful influences on prescribing behaviour of the clinicians subconsciously rather than overt. ${ }^{(1)}$ The drug 
companies are supposed to use the written material to show all the positive and negative aspects about the concerned drug for the drug promotion. These advertisements can be highly informative as long as they are critically appraised. ${ }^{(2,3,4)}$ Ideally, drug promotional literature should provide health care professionals with appropriate information. However, the information contained in promotional material can be inadequate, therefore making their interpretation difficult at time. ${ }^{(3,5)}$ The medical practitioners usually have no formal training that may assist them to evaluate and interpret these promotional materials. Irrational prescribing of drugs is still rampant despite of the existence of several guidelines that guide to evaluate the quality of promotional materials. Interns are exposed to these promotional material either during their medical course or during in internship. In previous studies ${ }^{(3,6,5,7,8)}$ drive home the fact that pharmaceutical companies do not adhere to the WHO guidelines specially with regard to safety information like drug interactions, precautions, side effects which may mislead the prescribers. Furthermore there is a void of education and training program among medical faculty except in their second year curriculum that consists of a single part of practical session. Therefore it is important to evaluate their knowledge about promotional brochures.

Therefore this study was conducted to evaluate the knowledge and impact of sensitization session amongst the Interns regarding WHO criteria for medicinal drug promotion and other necessary information needed before prescribing any drug.

\section{Materials and Methods \\ Objectives}

1. To assess the ability of Interns to identify violations of existing WHO guidelines as regards to interpretation of drug promotion.

2. To evaluate the impact of training interns on the topic of critical appraisal (as per the WHO guidelines ) of drug promotional brochures with a special focus on other essential information like Clinical trial results, medical body recommendation, Specialist testimonials, Significance of References presented in drug promotion, MOA , Comparison with other drug and Price of the drug .

3. To impart knowledge to the interns regarding information interpretation from Pharmaceutical Representatives and bribery in the form of incentives and gifts for commercial purposes from Pharmaceutical Industry.

This observational study was conducted in the B.J. Government Medical College and Sassoon General Hospital Pune, after getting approval from Institutional Ethics Committee.

In the first session, 25 promotional literatures were collected from drug companies from various clinical departments and a selected five of them were and presented to Interns. This exercise was performed to assess the baseline knowledge and ability of medical interns to identify violations of existing WHO guidelines that included 11 important parameters. Each Intern was asked to complete this task in one hour. Then they also had to answer a pre-test questionnaire. This was subsequently followed by the one hour session where lectures on critical appraisal methodology and the existing WHO guidelines on medicinal drug promotion were given .This session also covered other related important information required for prescribing any drug eg. indication, adverse drug reaction, monitoring, contraindications, drug interactions, pharmacokinetics, mechanism of action, comparison with other drugs, price, clinical trial results, medical body recommendation, specialist testimonials, significance of references presented in it. This was followed by small group discussions for 30min. In the third session same promotional literatures were given to all Interns again and post session evaluation by a post -test questionnaire. The scores obtained by the Intern in pre-test and posttest served as the pre and post-intervention 
measurements respectively. The criticism was evaluated using the checklist of WHO ethical criteria for medicinal drug promotion. For each correct parameter one mark was allotted and no marks were given for the wrong parameter. Also a missed parameter was given zero. As each Intern had evaluated each promotional literatures on the 11 point WHO scale; therefore the maximum score that could be obtained was 11. Post-test average responses were compared to respective pre-test responses for each intern, on the basis of standard promotional literature requirement parameters ${ }^{(9)}$.
The results were analysed using Student's paired t test using Graph pad prism 6 software.

\section{Results}

A total of 150 interns participated in this study. Table -1 show the pre and post-test average scores as per WHO parameter. When the pre intervention score was compared with that of post intervention, results showed that there was a statistically significant improvement in the latter as regards to most of the WHO criteria.(Table-1, Figure- 1)

Table- 1- Average score of parameters (out of 5) of Intern's evaluations of promotional brochures as per WHO criteria

\begin{tabular}{|l|l|c|c|c|c|}
\hline No & WHO criteria & $\begin{array}{c}\text { Pre Test- } \\
\text { Score }\end{array}$ & $\begin{array}{c}\text { Post Test- } \\
\text { Score }\end{array}$ & $\begin{array}{c}\text { Post-Pre } \\
\text { Test Score }\end{array}$ & P value \\
\hline 1 & Brand Name & 4.6 & 4.9 & $0.2 *$ & $<0.0257$ \\
\hline 2 & Generic Name & 2.5 & 4.2 & $1.7 * * *$ & $<0.0001$ \\
\hline 3 & Dosage Form & 2.6 & 4.9 & $2.3 * * *$ & $<0.0001$ \\
\hline 4 & Other ingredients known to cause problems & 0.1 & 0.9 & $0.8^{* * *}$ & $<0.0001$ \\
\hline 5 & Therapeutic use & 2.7 & 4.9 & $2.2^{* * *}$ & $<0.0001$ \\
\hline 6 & Side effect / ADR & 2.2 & 4.9 & $2.6^{* * *}$ & $<0.0001$ \\
\hline 7 & Precautions & 1.9 & 4.8 & $2.9 * * *$ & $<0.0001$ \\
\hline 8 & Major drug interactions & 1 & 4.8 & $3.7 * * *$ & $<0.0001$ \\
\hline 9 & Name and address & 0.1 & 2.3 & $2.2^{* * *}$ & $<0.0001$ \\
\hline 10 & References to scientific information & 0.3 & 2 & $1.7 * * *$ & $<0.0001$ \\
\hline
\end{tabular}

$* \mathrm{p}<0.05-$ statistically significant, $* * * \mathrm{p}<0.0001$ highly statistically significant value. Values are expressed as mean and mean difference between Pre-test and Post- test for that parameter.

Figure 1 Graphical representation of (Table -1) Difference between Post Test and Pre Test scores of Intern's on evaluation of promotional brochures as per WHO criteria

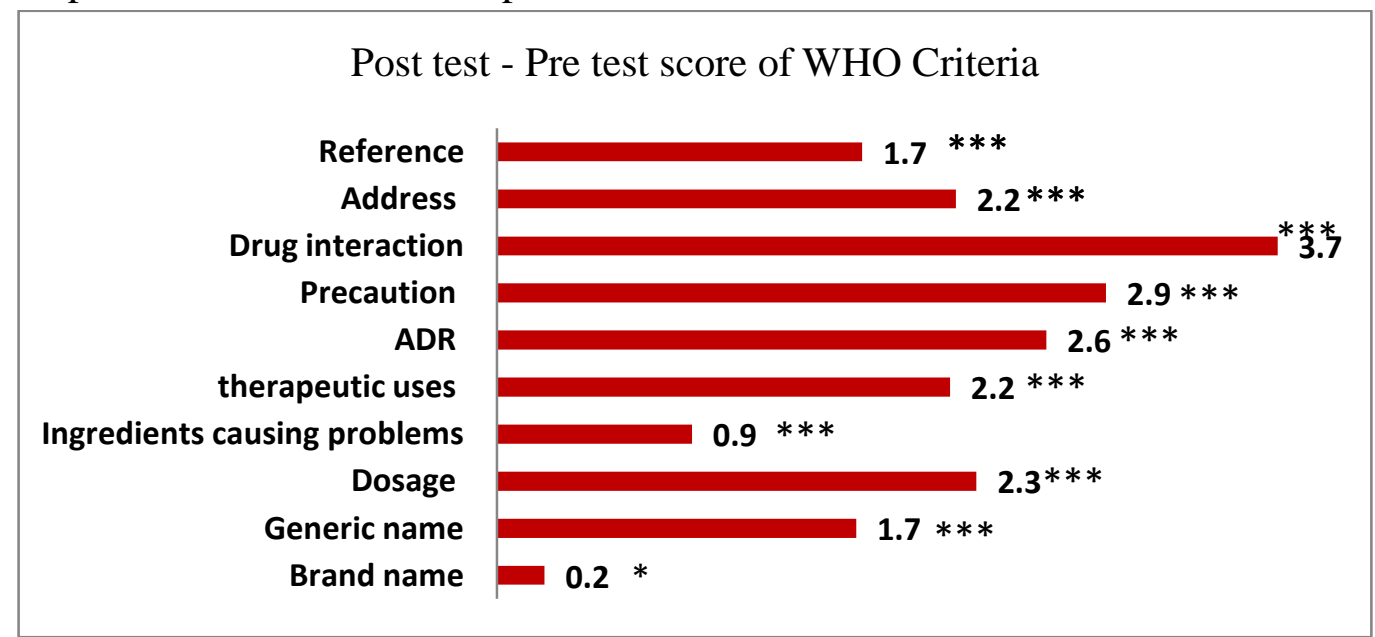

$* \mathrm{p}<0.05$ - statistically significant, $* * * \mathrm{p}<0.0001$ highly statistically significant value. Values are expressed as mean difference between Pre-test and Post- test for the respective WHO parameter.

A significant improvement was observed in Interaction, Precaution, ADR, manufacturer's student's performance. There was specifically a address and references. (Table-1, Figure -1) distinct improvement seen related to Drug 
Figure-2 Awareness of medical Interns about the significance to include safety parameters in a drug promotion literature

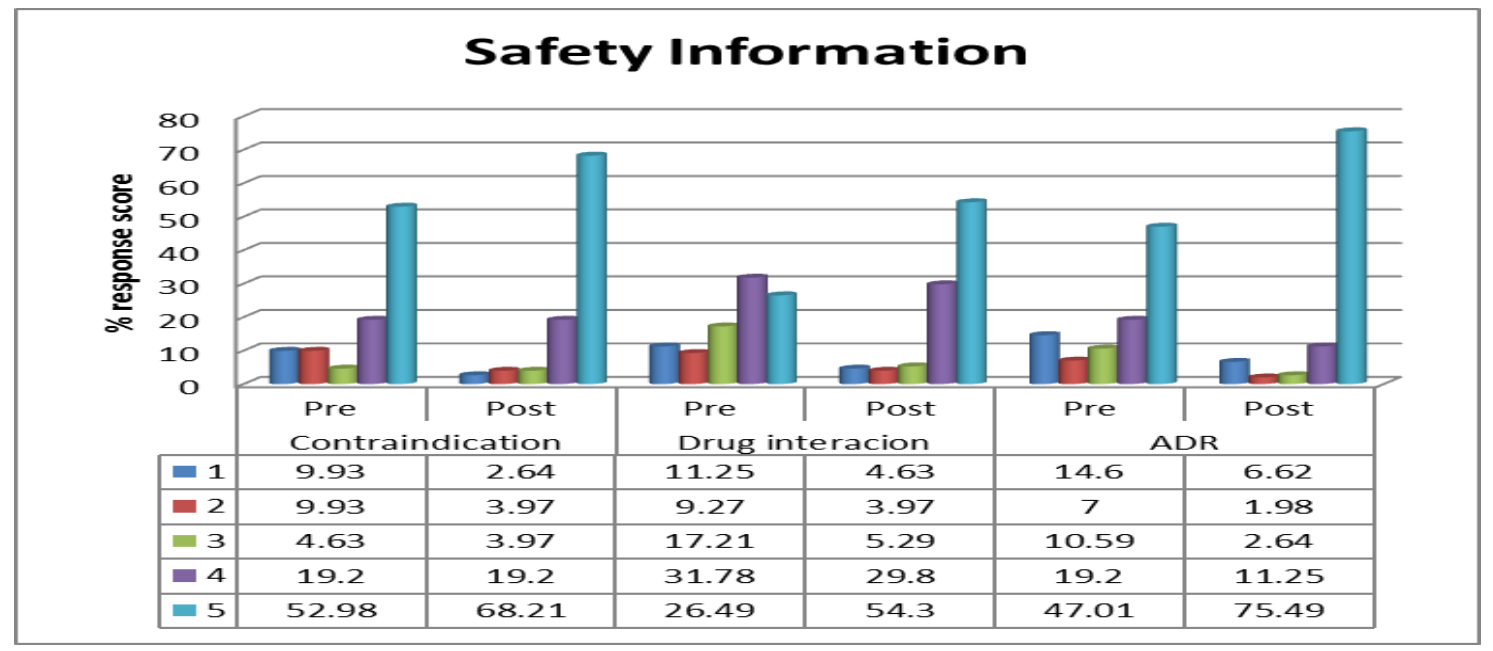

Likert score -5 point scale were $5=$ most significant and $1=$ least significant. On $\mathrm{X}$ axis: $\%$ response of Interns perceived Likert score for significance of various type of safety prescribing information. Values are expressed as mean

In Figure -2 the medical interns were evaluated on their awareness about the significance to include safety parameters in a drug promotion literature like adverse drug reaction, contraindication and drug interaction. The response of the interns were recorded on the Likert scale where $1=$ least significant and $5=$ most significant for mentioning the safety parameters on the promotional drug literature. There was improvement in post test scores as regards to their awareness about significance to include safety parameters in a drug promotion literature.

Figure- 3 Awareness of medical Interns about the significance to include pharmacological information in a drug promotion literature

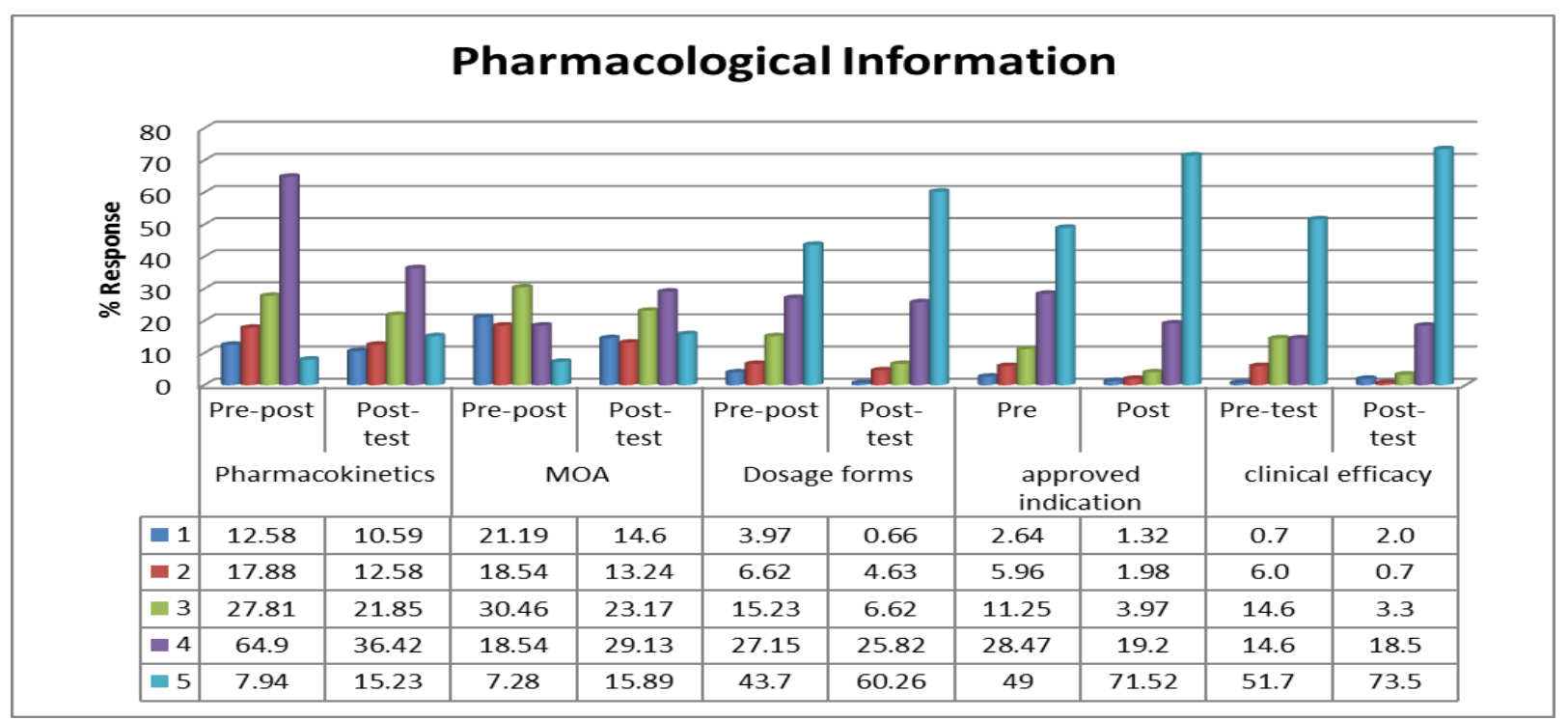

Likert score derived from 5 point scale where $5=$ most significant and $1=$ least significant.On $\mathrm{X}$ axis: \% response of medical interns perceived Likert score for significance of various type of pharmacological information.

In Figure - 3, it was observed that, according to the interns, information regarding approved indication (49\%) and clinical efficacy (57.1\%) was the most important; rather significant data included in any promotional literature. On the contrary they regarded information like, mechanism of action (7.28\%) and pharmacokinetic data $(7.94 \%)$ as not significant to be mentioned in the promotional literature. $43.7 \%$ of the medical interns also perceived that the information of various dosage forms was significant to be mentioned in the promotional 
drug literature. This in post-test this percentage changed to $60.26 \%$ on most significant Likert score scale that is 5.Similarly after the training session the interns gained awareness that pharmacological information is important to mention it in the promotional literature as per WHO guidelines.

Figure- 4 Awareness of medical Interns about the significance to include other prescribing information pharmacological information in a drug promotion literature

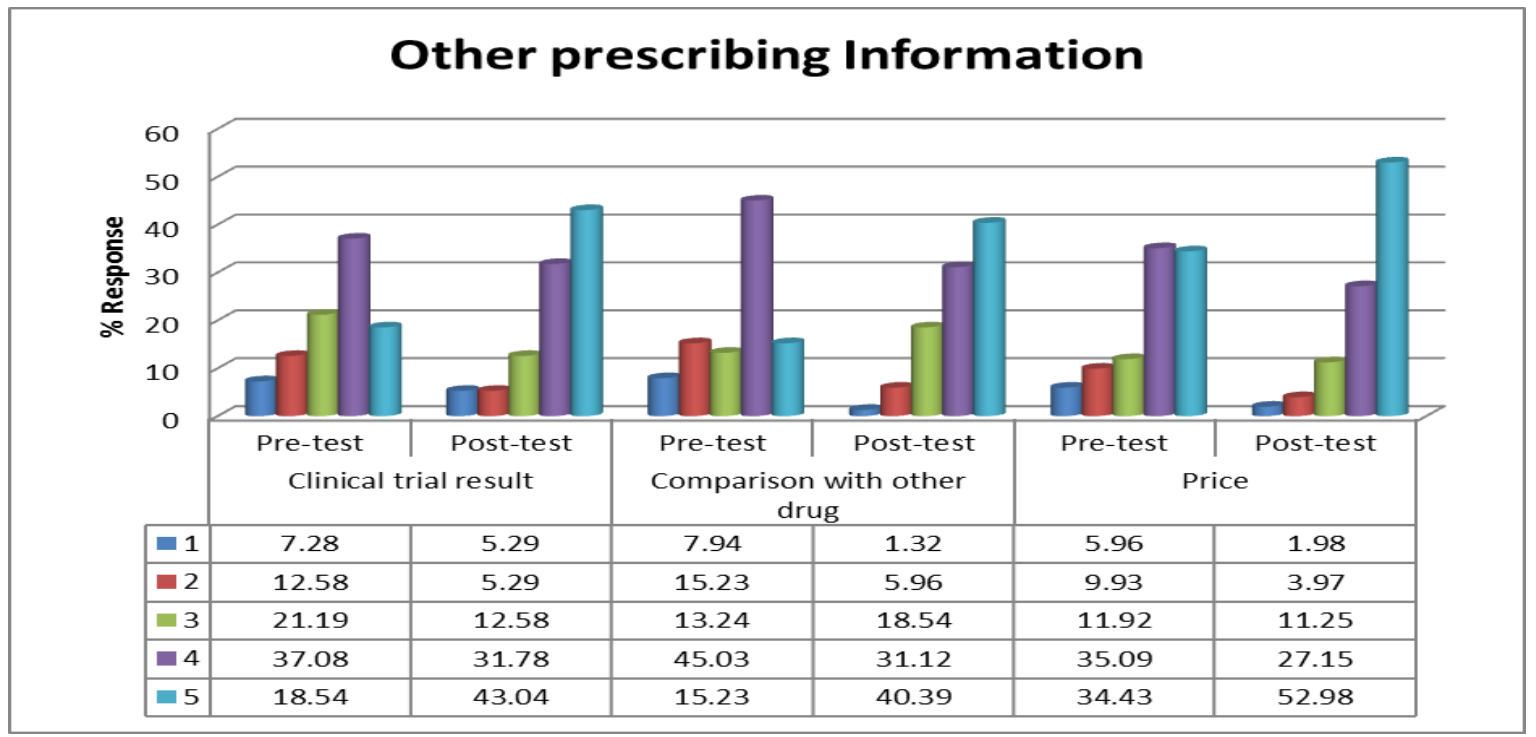

Likert score derived from 5 point scale were $5=$ most significant and $1=$ least significant. $\mathrm{X}$ axis: $\%$ response of medical interns perceived Likert score for significance of other prescribing information.

In Figure -4, the knowledge of the interns the about significance of including data regarding comparison with the other drugs changed from $15.23 \%$ to $40.39 \%$ (on $5^{\text {th }}$ point Likert score). Similarly information regarding price changed from $34.43 \%$ to 52.98 (on $5^{\text {th }}$ point Likert score). This type of information is needed for refining the prescription for better alternative while they prescribe drug especially related to price.

Figure - 5 Students Response for Significance of Reference Appeared in promotional literature

\section{Students Response For Significance Of References Apperard In Promotional Literature}

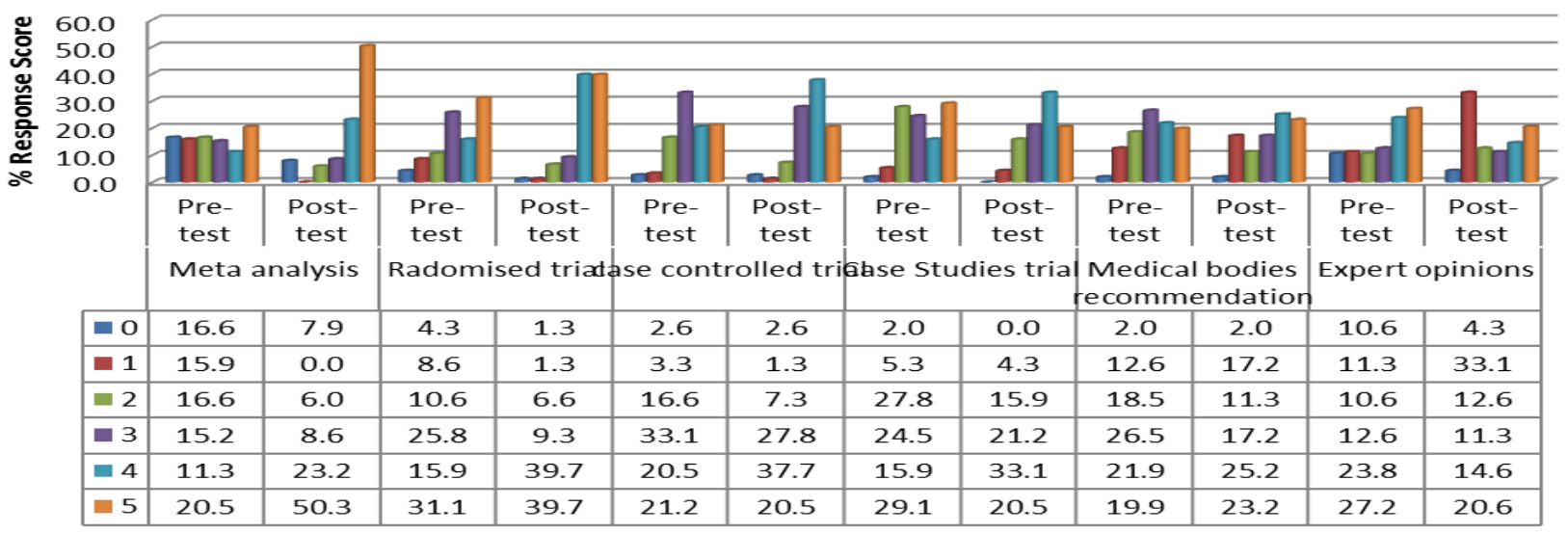

Likert score derived from 5 point scale were $5=$ most significant and $1=$ least significant. X axis: $\%$ response of Interns perceived Likert score for significance of several of evidences presented as references in the promotional literature

The Figure- 5 shows the interns became more scientific evidences in evaluating promotional aware about the importance of supporting literature, after the training session. Meta-analysis 
trial and Systematic reviews of randomized controlled trials are the strongest level of evidence (i.e., Level I evidence). Other levels of evidence in descending order of strength include nonrandomized trials, case-control studies, medical bodies recommendation, Expert opinions, reports of expert committees. Meta-analysis was rated on the scale before training was $20.5 \%$ for $5^{\text {th }}$ point but after training it changed to $50.3 \%$. Regarding expert opinions recommendations considered significant before then it convert to lest significant evidence $\left(27.2 \%\right.$ change to $20.6 \%$ on $5^{\text {th }}$ point Likert score).

Table-2 Training interns about how to deal with Medical Representatives and develop the skills to evaluate promotional literature

\begin{tabular}{|c|c|c|}
\hline Objectives for education about drug promotion & Yes & No \\
\hline Teach skill in critical appraisal DPL & $85.4 \%$ & $14.6 \%$ \\
\hline To change Interns attitudes towards DPL and MR & $79.5 \%$ & $20.5 \%$ \\
\hline Behaviours related to gifts & $59.6 \%$ & $40.4 \%$ \\
\hline To improve to extract beneficial information from DPL & $89.4 \%$ & $10.6 \%$ \\
\hline To improve to use independent information sources other than DPL & $70.9 \%$ & $29.1 \%$ \\
\hline To increase use of drug promotion literatures & $35.1 \%$ & $64.9 \%$ \\
\hline To decrease use of drug promotion literatures & $36.4 \%$ & $63.6 \%$ \\
\hline Is it a part of curriculum for all medical students & $92.7 \%$ & $7.3 \%$ \\
\hline Awareness' of guidelines toward gifts & $96.0 \%$ & $4.0 \%$ \\
\hline Help in future rational practice & $96.0 \%$ & $4.0 \%$ \\
\hline Provide knowledge about new topics & $96.0 \%$ & $4.0 \%$ \\
\hline Session was informative & $98.0 \%$ & $2.0 \%$ \\
\hline Learn how to deal with MR & $98.0 \%$ & $2.0 \%$ \\
\hline
\end{tabular}

DPL- drug promotion literatures, MR- medical representatives

96\% Interns reported increase in awareness as regards to the concept that accepting small gifts is also bribe, develop an independent drug information $(70.9 \%)$ other than promotional literature. $98 \%$ reported that they learnt how to deal with medical representatives. $92.7 \%$ interns agreed such type of training is a part of curriculum for all medical students.

Figure -5 Percentage of intern's response after teaching session

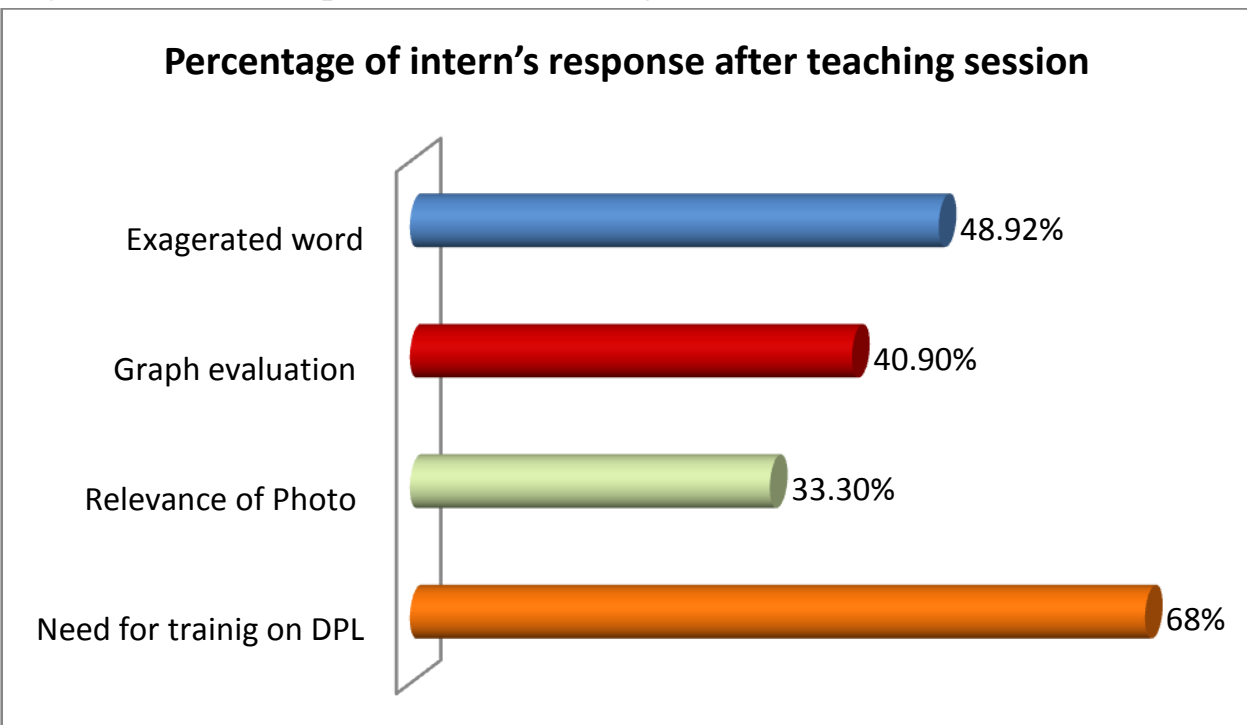

Figure no. 5 shows that after the training session medical interns were able to identify the violations correctly after the training session. $68 \%$ of Interns commented that such training was needed for future rational drug practice for identifying violations that appeared in promotional literature. $48.92 \%$ interns were able to identify for violation of exaggerated word used in promotional literature. Whereas, $40.90 \%$ were able to perform a better graph evaluation after the training. 
Figure No.6: Percentage of success of educational programme on the drug

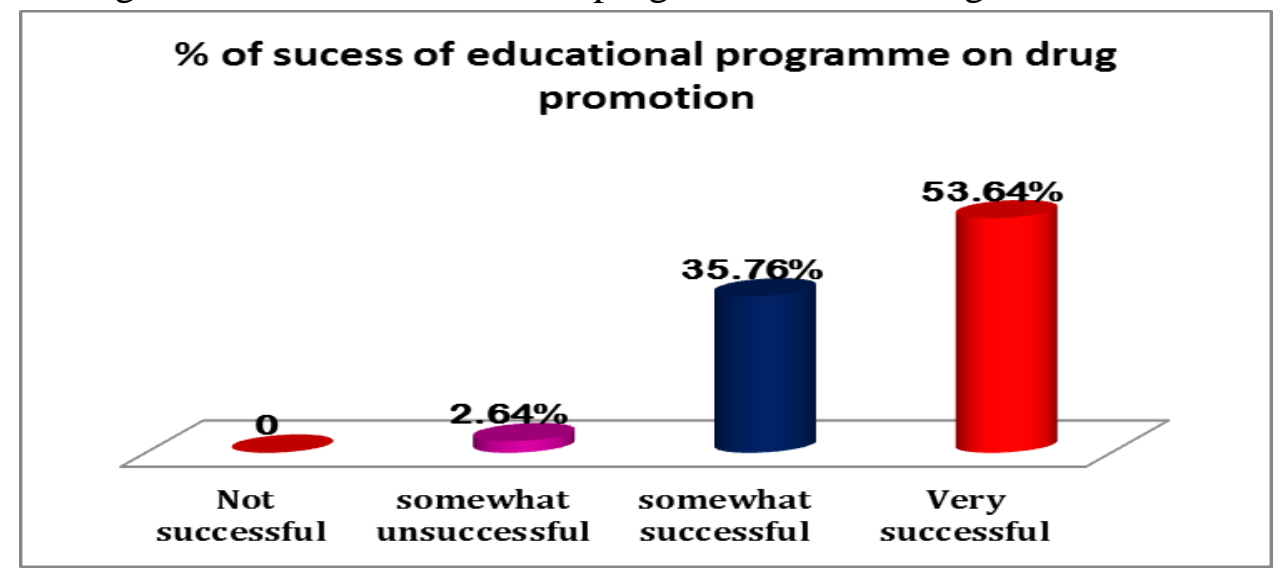

In figure no. 6 the interns reported that such type of training was very successful $(53.64 \%)$ and not a single intern reported failure of the teaching programme.

\section{Discussion}

Drug promotional literature is the most important tool for any pharmaceutical company to augment their sales. Doctors are exposed to such promotional material on routine basis and are also reinforced for prescribing the said drug. It is the right and responsibility of the doctor to choose the optimum best treatment for his/her patient. This is possible if they are made aware of the appropriate method to interpret such promotional literature.

This study involved 150 medical interns. A statistically significant improvement was found in not only knowledge of the interns, but also in the commenting and criticizing abilities, due to the training program. Various studies are conducted by numerous authors ${ }^{(1,11,4)}$ on teaching critical appraisal of promotional brochures in a medical college. They concluded that post intervention scores were significantly higher in the participants who underwent the teaching module on critical appraisal of medicinal drug promotion.

The present study lays the emphasis on the importance of training medical professional on critical appraisal of drug promotional literature, early in the medical career. To train medical interns to identify violations of WHO guidelines governing drug advertisement. Low pre-test score can be attributed to lack of specific training or inadequate emphasis on evaluation of drug promotional literature, in routine medical education curriculum. So training medical interns to evaluate and criticise promotional literatures appropriately make the interns more adept for future clinical practice ${ }^{(12)}$ There was significant improvement in the knowledge of Generic name post-test (1.7) and for Dosage forms (2.3). Addressing the adverse drug reaction in promotional literature is a necessary part of the WHO criteria as it strengthens the pharmacovigilance reporting from grass root level for physician. As regard to such training there was a significant improvement in post test score in Interns indicating the importance of such training (Table-1).

References are an integral and important part of drug promotion yet many times they are missing, neglected or mentioned in very small font size which is not readable. References give the authenticity for claimed or indications in the promotional literature. After training, statically significant improvements $(\mathrm{p}<0.0001)$ were observed in ability of Interns to comment appropriately about the references in the promotional literature. Doctors should be able to identify and analyse the correctness and authenticity of such statements that may make tall claims. Similar results were obtained in a study conducted by other authors ${ }^{(13,14,15)}$.In this study there was a significant improvement in post test scores with regard to look for information about safety parameter like adverse drug reaction (47\% changedto75.49\%), contraindication and drug interaction (26.49\% changed $54.3 \%)$. Interns 
were unaware that one has to observe the said parameter in promotional literature. These parameters are an important part of training as promotional literature may be one of the important or seldom sole of information provider in a busy practitioner. This training will help the interns to increase awareness about safe drug prescribing habit.

With regard of approved indication and clinical efficacy the interns seek the information present on the promotional literature. According to them the information regarding the mechanism of action and Pharmacokinetic data is not that much important for prescribing any drugs. But they want the information of various dosages which reflect in post-test response $43.7 \%$ changed to $60.26 \%$ on most significant scale that is 5 .

In this study interns wanted to seek knowledge the about comparison with the other drugs ( $15.23 \%$ changed to $40.39 \%$ on $5^{\text {th }}$ point score) or price $\left(34.43 \%\right.$ changed to 52.98 on $5^{\text {th }}$ point score). This type of information helped to prescribe a better alternative while they prescribe drugs. Supporting scientific evidences is an important aspect to be considered in evaluating promotional literature and the authenticity of the claims made by the company. Meta-analysis trial and Systematic reviews of randomized controlled trials are the strongest level of evidence (i.e., Level I evidence). Other levels of evidence in descending order of strength include nonrandomized trials, case-control studies, medical bodies' recommendation, Expert opinions, reports of expert committees ${ }^{(10) .}$ Meta-analysis was rated on the scale before training was $20.5 \%$ for $5^{\text {th }}$ point but after training it changed to50.3\%. Regarding expert opinions and medical body recommendations considered most significant before then it convert to less significant evidence.

Medical students are given minimal formal training on evaluation of drug promotional literature during their curriculum. When they commence medical practice they may be influenced by the vigorous marketing, gifts and other promotional strategies like sponsorships to various conferences, CME etc. offered by pharmaceutical Industry. The training session highlighted on the policy towards non- acceptance of the gifts.

Interns were able to identify and analyse the relevance of images (33.30\%), Graphical evaluation (40.90\%) and, use of exaggerated word $(48.92 \%)$ given on the promotional drug literature used in this study. Images and slogans in brochures attract the attention of prescribers. Interns also reported their comments as this session was useful for future practice, they also able to identify that improper graphs axis, irrelevant photos and exaggerated word used in promotion literature. Therefore physicians and medical professionals should be able to identify and analyse the correctness and authenticity of such statements that may make tall claims. Similar results were obtained in a study conducted by $\mathrm{H}$. Nagabushan et al and Hasina et al (2017).

\section{Conclusion}

This study shows the importance of teaching "critical appraisal of drug promotional literature" in medical interns. It is reasonable to conclude that the problem of irrational drug use may be significantly reduced if not totally eliminated if prescribing doctors were able to critically appraise the claims made in drug promotional materials. Future prescribing practices will be improved if the necessary skills and critical attitudes for rational therapy are strengthened during the internship of medical undergraduates.

\section{References}

1. Avorn J, Chen M, Hartley R. Scientific versus commercial sources of influence on the prescribing behaviour of physicians. American Journal of Med 1982;731:4-8.

2. Levy $R$. The role and value of pharmaceutical marketing. Arch. Fam. Med 1994; 3:327-32.

3. Hasina Sayyad, Ghongane B.B and ShahidSaache.Evaluation of drug promotional brochures using who 
guidelines, teaching critical appraisal of it in medical students.Int $\mathrm{J}$ Pharma Bio Sci 2015 Oct;6(4): (P) 494-501.

4. Hasina sayyad, Ghongane B.B, Shahidsaache, Smita Tiwari .Teaching critical appraisal of drug promotional brochures on ability of medical students to identify violations of existing WHO Guidelines IOSR Journal of Dental and Medical Sciences Volume 16,Issue 2 Ver. I (Feb2017), PP43-48

5. Mali Smita N., Sujata Dudhgaonkar, and N.P. Bachewar, Evaluation of Rationality of Promotional Drug Literature Using World Health Organization Guidelines. Indian Journal of Pharmacology, 42(5):267-272. (2010).

6. VV Shetty, AV Karve. Promotional literature: How do we critically appraise? Journal of Postgraduate Medicine 2008; 54:217-21.

7. Ehab Mudher Mikhael, Evaluating the reliability and accuracy of the promotional bro-chures for the generic pharmaceutical companies in Iraq using World Health Organiza-tion guidelines. J Pharm BioalliedSci, 7(1): 65-68, (2015).

8. Alam K, Shah AK, Ojha P, Palaian S and Shankar PR, Evaluation of drug promotion-al materials in a hospital setting in Nepal. South Med Rev, 2(1):2-6, (2009).

9. Criteria for Medicinal Drug Promotion, World Health Organisation. Endorsed by the 33rd World Health Assembly, May 1986, Resolution No.WHA21.41. Available:

http://apps.who.int/medicinedocs/en/d/Js1 6520e/6.html.Accessed 12 January 2016.

10. Cooper RJ, Schringer DL. The availability of references and the sponsorship of original research cited in pharmaceutical advertisements. Canadian Med Assoc J. 2005;172:487-91.

11. Alvero RGY and Panganiban DL, Teaching critical appraisal of medicinal drug promotions in a medical school. World Health Organization, 2008. Available at http://archives.who.int/icium/icium1997/p osters/2a1_text.html Cited on 2015 June.

12. Mintzes B. Educational initiatives for medical and pharmacy students about drug promotion: an international cross-sectional survey. World Health Organization and Health Action International; 2005.

13. Dr. H. Nagabushan, Dr. N.S. Shashikumar. Training and development of medical trainee's on critical appraisal of drug advertisement in medical college, Mandya. International Journal of Universal Pharmacy and Life Sciences. 2013; 3(3):78-87.

14. Ravinder K. Saha, Rakhamaji D. Chandanea, Anita H. Yuwnateb, Manik S. Ghadlingec, Sumitkulharea Knowledge and practice of prescribers regarding who ethical criteria for drug promotional advertisements , ejpmr, 2016,3(11), 52252

15. Rohit Dixit1, Prabhakar Patil2, Chandrashekar3, Rajesh C S1, Sudha Madhuri1, Abhay Mane4; Drug promotional activities as a source of medical information and its influence on prescribing, IJPBS ,Volume 4, Issue 3,JulSept,2014,113-119 